\title{
3D Laser Recording and the “Naturalised" Urban Landscape of Göreme, Kapadokya, Turkey
}

\author{
Carmela Crescenzi \\ Università degli studi di Firenze, Dipartimento di Architettura (DIDA) \\ email: carmela.crescenzi@unifi.it \\ Marcello Scalzo \\ Università degli studi di Firenze, Dipartimento di Architettura (DIDA) \\ email: marcello.scalzo@unifi.it

\section{Giorgio Verdiani} \\ Università degli studi di Firenze, Dipartimento di Architettura (DIDA) \\ email: giorgio.verdiani@unifi.it
}

\section{Abstract}

This paper presents research on the historic urban settlement and natural landscape between the Göreme and Kiliclar (Swords) valleys, located in Kapadokya, one of the most distinctive human and natural landscapes in the world, inscribed on the UNESCO World Heritage List in 1985. The research was part of the Italian Scientific Research Programs of Relevant National Interest (PRIN) programme Rupestrian Art and Habitats in Kapadokya (Turkey) and in Central and Southern Italy - Rock, Excavated Architecture, Painting: Between Knowledge, Preservation and Enhancement. The study area has all the features of rupestrian Mediterranean culture, encompassing a heritage developed over time with environmental, architectural and artistic elements. It tells a special story about ancient life, completing and widening our comprehension of the past. There are buildings of great architectural and pictorial qualities, such as the Tokali Kilise, Saint Eustachius and Saint Daniel, where it is still possible to read the old defensive system and the local way of life. Yet these cave settlements are at risk from deterioration. The research is centred on survey, especially on a digital survey carried out using 3D laser scanners for the architecture as well as of the natural stone structure of the settle-

ment. In this way the first complete and detailed documentation of this area has been created, allowing the first studies on the urban character of this archaeological site. The research presented here will show a fully digital approach using 3D digital models aimed to investigate, read, preserve the information and disseminate the artistic and cultural values otherwise not easily accessible and continuously at risk of loss because of decay processes.

Keywords: Rupestrian; Turkey; Kapadokya; 3D Laser Scanner; Digital Survey

\section{Introduction}

Kapadokya is located in the centre of Turkey in an area of volcanic origin which through time has been eroded to become an extraordinary landscape which today looks stunning to the eyes of visitors. The natural appearance suggesting an organisation based on "built" elements has certainly inspired the first inhabitants of these areas and the long line of their successors, who carved and excavated the rock masses to create shelters, stores, homes, churches, castles, farms and entire cities (Andaloro et al, 2013). So the rock has been
\end{abstract}


weakened and crumbled and the whole of the excavations, while richly defining the territory, have also accentuated the degradation and the natural wear of the material, collapsing and transforming interiors into façades, showing beautiful details in the process of dissolution: a rich collection of fleeting wonders. The drama of the state of degradation has become itself an added value of the landscape. The collapse of the structures has transformed the interior sculpture of the places into external facades; this shows the beauty of details in the dissolution process: it is a rich collection of fleeting wonders. In this context, there are a large number of exceptional monuments. Some of them are well preserved and offer a great opportunity for research to improve the knowledge of the period (Andaloro, Bixio \& Crescenzi, 2013). Thus, while the natural character of the territory motivated the ancient inhabitants to carve out their settlements over a very long period of time, the creators of the beauty of these places are the same who will cause its end: human pressure and climate actions has lead to the collapse of the settlements built over the centuries.

It is in this rich and complex context, with the permission of the General Direction of the Ministry of Culture and Tourism of the Republic of Turkey, that the research mission of DISBEC (Department of Cultural Heritage Science, Viterbol from the University of Tuscia Rock Painting in Cappadocia. For a Project of Knowledge, Conservation and Enhancement, directed by Maria Andaloro, has taken place. At the same time the Dipartimento di Architettura (Architecture Department, DIDA) from the University of Florence carried out the European CHRIMA-CINP Project ICultural Rupestrian Heritage in the Circum Mediterranean Area Common Identity, New Perspectivel coordinated by Carmela Crescenzi (Crescenzi \& Verdiani, 2013), and completed in 2012. These projects followed an interdisciplinary methodology, linking humanistic knowledge with scientific and technical investigations. The teams included art historians, archaeologists, chemists, photographers, architects, geologists and speleologists. DISBEC and DIDA now work as partners in the PRIN project (Italian
National Relevance Research Project) approved in 2013 Rupestrian Habitat and Arts in Cappadocia, Turkey and in Centre-South Italy - Rock, Carved Architecture, Painting: Between the Knowledge, the Conservation and the Enhancement. In this new research project the working group was extended to other partners like the University of Calabria, the University of Rome, the National Research Centre (CNR ) in Rome, the Centro Studi Sotterranei in Genoa (Underground Study Centre, Genoa) and others. The main fieldwork presented here was by the unit from DIDA. The first common activities between UNIFI and UNITUS units took place at the Tokali Kilise (the Buckle Church). In this research the creation of 3D digital models, starting from an accurate digital survey, aims to display the paintings in the excavated churches that host them, allowing a deeper and clearer knowledge of the rupestrian habitat in all its components (Andaloro, Bixio \& Crescenzi, 2013). This kind of documentation will be very useful for the realisation of innovative instruments of fruition such as virtual reality installations and other multimedia products for visitors. Between 2012 and 2014, a large part of the rupestrian settlements in front of the "Open Air Museum" area was surveyed in detail, with particular attention to the relationship between the landscape and its special architecture.

\section{A Naturalised Urban Landscape}

The Göreme area has all the features of the extensive rupestrian culture spanning the Mediterranean and encompassing a heritage developed over time with meaningful environmental, architectural and artistic elements (Jolivet-Lévy, 1991). The beauty of the place is due to the plastic properties of the volcanic stones, from which slow and inexorable erosion over thousands of years has created wonderful natural landscapes, which now also contain traces of numerous human settlements. In Göreme there are two main types of settlement: linear settlements following the ridge of the Kiliclar valley and "islands" built in the rock pinnacles. There are buildings of great architectural 
and artistic values, such as the monumental Tokali Kilise, Saint Eustachius, Saint Daniel, the Meryemana Church. There are also all the minor systems of small churches and tangled rooms where it is still possible to read the historical defensive system and see traces of everyday life, facilities and infrastructure that coexisted in a single settlement guaranteeing quality of life and safety for the inhabitants (De Pascale \& Bixio, 2015).

In short, the rupestrian sites in Göreme are a sort of collection of fragments of ancient architectures (Bixio \& Castellani, 1995). They are part of a common and distinctive feature of the Mediterranean landscape which has continuity in time and space and involves all social strata. Man has excavated structures in the rocks from the Anatolian highlands to the Egyptian deserts, from the Balkans to Italy, from France to Spain. In this anthropological and ethnographic context, the artificial cave can be seen as one of the "common houses" of Mediterranean culture. The cultural unity of rupestrian settlements was, in some cases, damaged or destroyed, but their relevance as open air eco-museums has never been underestimated, despite deterioration and erosion caused by the weather (Crescenzi, 2012).

This use enhances the natural value of the area, creating a complex mosaic of natural and human works. The area has been explored and documented during the past century, although the focus has mainly been captured by religious buildings, especially those enriched by mural paintings (Jolivet-Lévy, 2002). In recent years, the value of secular structures, the urban settlements themselves, has been recognised and the first studies about the urban systems and their articulation in the landscape have begun. These rock-cut cave structures tell a special story about ancient life, but they are continuously at risk of deterioration (Bixio, Castellani \& Succhiarelli, 2002; Bixio et al, 2012). This can be seen in the villages of Cavușin and Zelve, where two rock falls have exposed a cross-section of the unique urban contexts excavated in the rock. The disaster has created a sort of wonder, a real "section" through the remains that creates surprise in all the visitors.

\section{Three Examples of the Relationship be- tween Rupestrian Architecture and Land- scape}

In studying a large area in Göreme, interest can be captured by many specific parts. In this research there have been three main focuses: the church of Saint Eustachius, the church of Saint Daniel and the Meryemana Church. They have very different conditions and complexities. Their relationship with the landscape is quite different, Saint Eustachius and the Meryemana belonging to linear developments, connecting at many points the edge of the Kılıçlar valley (Swords Valley) to the Göreme valley, while Saint Daniel has an island structure and is carved in a group of peaks, also in the Göreme valley.

The churches of Saint Eustache, the Meryemana (the House of Maryl and Saint Daniel are perfect examples of complex rupestrian settlement - the church, all the spaces of ancient life - but they are only partly readable and recognisable. The churches are largely well preserved in their main rooms. The settlement takes its name from the church of Saint Eustachius hollowed on top of the pinnacle, from where it dominates the area. The south-western face of the complex overlooks the valley of Göreme and its church could communicate visually with the rupestrian settlement of Uchisar (the "Pointed Castle") excavated in a natural tuff tower, three kilometres south-west at the head of the erosion valleys district, perhaps used as sighting point (fig. 1). The visual relationship with Uchisar is clear once the place is reached, looking from the openings of the refuges and from the church itself. Besides Uçhisar, the last castle, the defensive territorial system could also rely on Bașhisar (the first castle) and Ortahisar (the middle castle), this last about 100 metres high, a fabulous tower in the middle of small houses, completely excavated within a single peak. At a lower level is a hollowed elaborate system of housing with numerous structures supplied with defensive systems. 


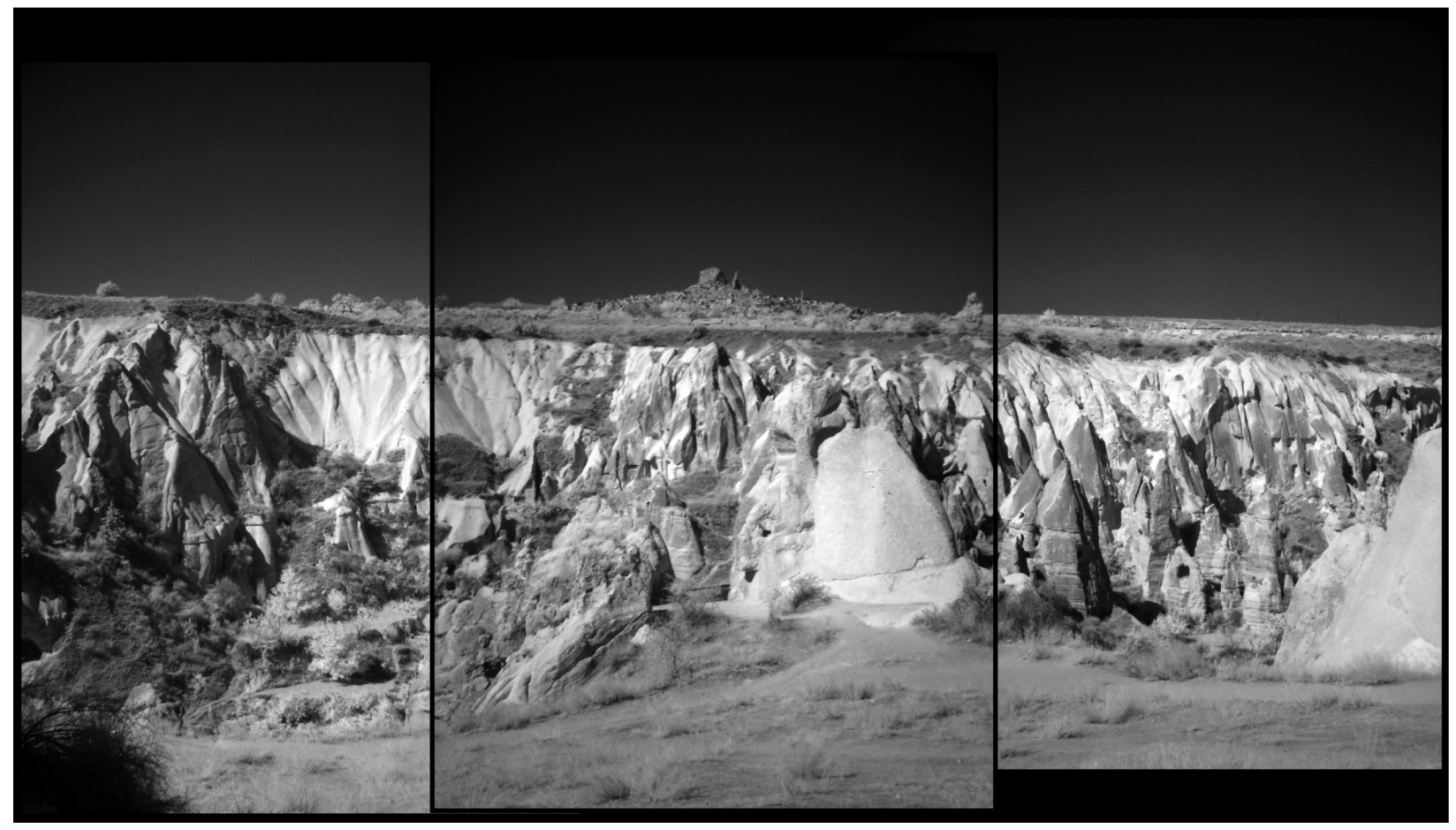

Fig. 1. Infrared View from Saint Eustachius Church towards the Uchisar Castle (copyright G. Verdiani).

The Saint Daniel church belongs to a group of rocky peaks containing places of worship and a convent, a specific system of refuges, and two churches: one dedicated to Saint Daniel, with still intact wall paintings, the second church, non-iconic, typically decorated with geometric red patterns. The degradation and the fragility of the paintings in the first church (hence it is perpetually closed) and the fragmentary nature of the space make it difficult to read the complex which is still arranged in three levels along the peaks. The church of Saint Eustache, enhanced by a beautiful and richly painted barrel vault, currently has its entrance about four metres higher than the ground level reached by the access trail. The case of the Meryemana shows its dramatic situation. It is a rupestrian church of great beauty, used as one of the set locations for the movie Medea by Pier Paolo Pasolini in 1969, but it is now the most striking in terms of degradation. The place has always been difficult to reach because it has few entrance passages, but now it is perma- nently closed to the public because of the imminent threat of collapse. The House of Mary is also afflicted by a large crack that divides the whole church into two parts, allowing water to percolate down on the wall paintings. It is threatened by the impending collapse of the seventeen metres high peak above the church into the hollow of the valley $25 \mathrm{~m}$ below (Andaloro, Pignatale \& Verdiani, 2013; Crescenzi, Di Tondo \& Verdiani, 2012).

After their completion, the project's digital surveys allowed an immediate reading of the structures. In the settlement of Saint Eustachius, for example, it is evident that its underground system is an example of an ancient system for living combining worship, farming and defensive activities. Four shelters have been localised and surveyed. They were connected to tunnel-shaped water cisterns excavated in the riverbed of the Kılıçlar valley, on the opposite side of the Göreme valley. This canyon is additionally crossed through its longitudinal axis by artificial drainage tunnels, still usable, that allowed the valley bottom to be used for farming. 


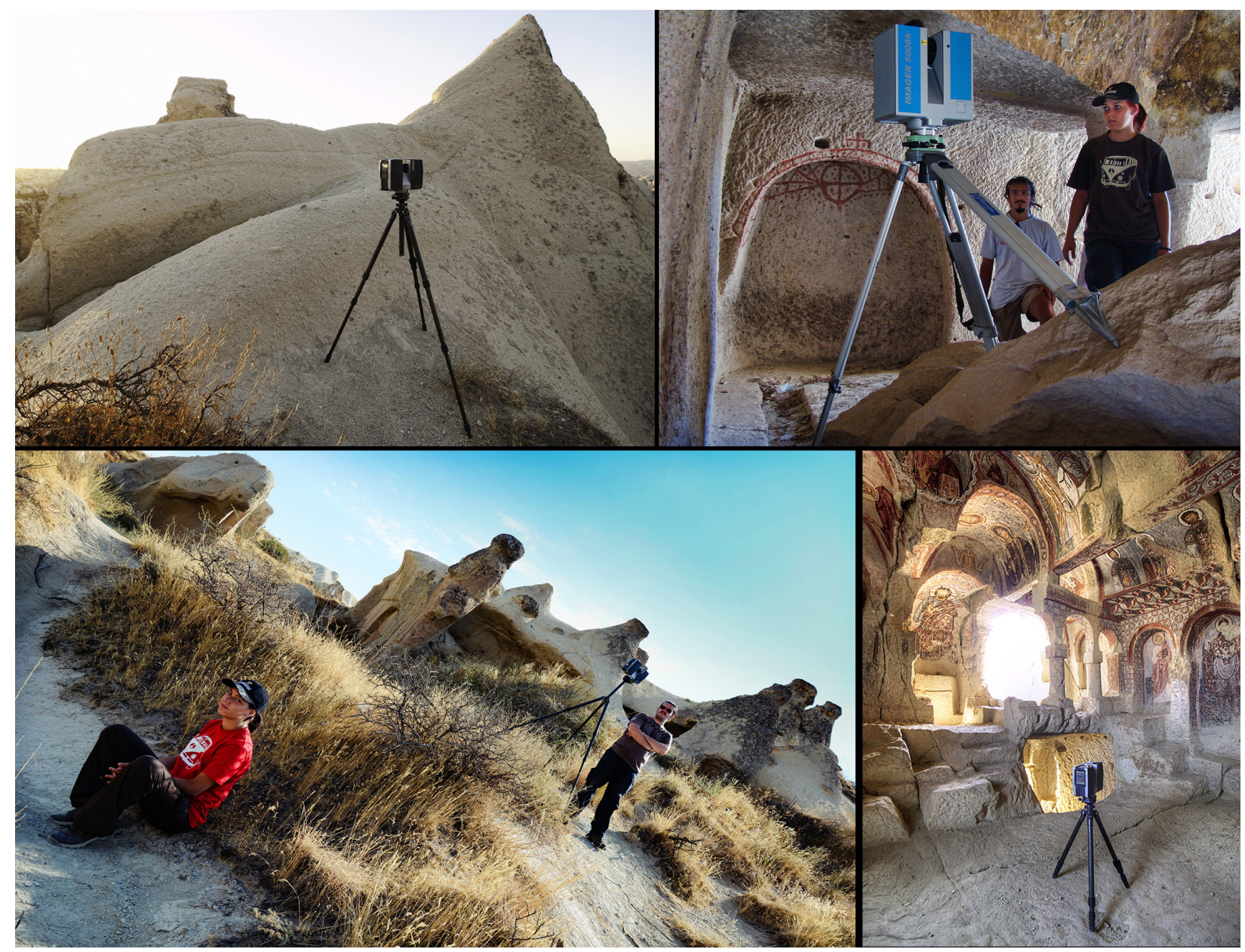

Fig. 2. The 3D laser scanners at work along the valleys and in the internal spaces (copyright G. Verdiani).

\section{Digital survey operations}

The research of the DIDA unit is centred on a digital survey carried out by mainly using 3D laser scanners to document architecture as well as the natural stone structure of the settlements. In the survey campaigns from 2012 to 2014, three main 3D Laser Scanner Units were used (fig. 2), a Cam/2 Faro Focus, a Z+F 5006h and a Riegl VZ 400 long range unit. To compose all the scans into a single model required the accurate post-processing work of matching and alignment and it was done using both specific target systems and geometric similarities in overlapping parts of the scans. The rock material of the whole area turned out to re- flect the signal of the laser effectively, responding well to the phase variation measurement operated by the scanners and also making the gathering points easy from the maximum operative distance. Even at the longer operating distances provided by these tools, the points were taken with good density. Despite the common good quality of the long distance points, it was decided not to use these points directly as references for the alignments, but to use the points closer to the scanner. These areas have proved to be clearly legible without causing any mismatch phenomena, making it possible to produce the vision of an organic and detailed space from the aligned point clouds, a model able to describe accurately a picturesque landscape that is otherwise afflicted by a difficult geometric representation.

Although the stone surface has responded well to the signal of the laser, the application of planar 


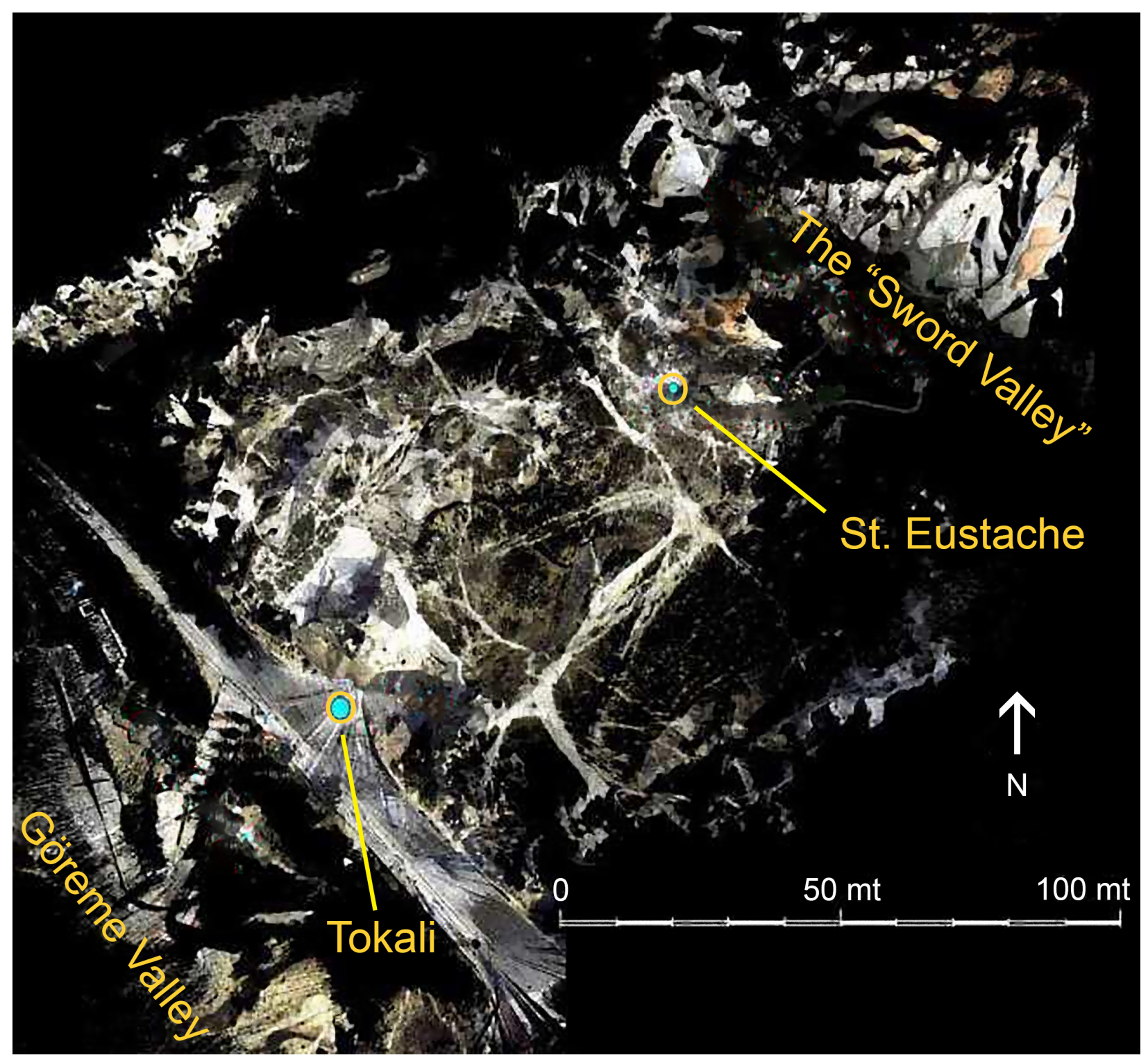

Fig. 3. View of the set of 3D scans from the 2012 survey campaign.

targets, which are commonly used on architectural structures, has proved to be difficult because the soft shapes and the organic surfaces of the stone are brittle and have a sandy layer. These features, together with the environmental conditions (the wind wedged in the spaces, temperature changes between day and night and sometimes a high level of humidityl have strongly limited the use of temporary targets fixed on the walls or in the area nearby. There were too many problems for the stability of the targets. The implementation of some mobile targets and the recognition of morphologic elements (such as spots, cracks, signs or small stones) for the following alignment of the scans were preferable options. For this reason, it was preferable to maintain a certain degree of overlap between each single station and to position the scanner in conditions where it was capable of facilitating the recognition of common elements from one scan to the following.

In this way the first complete and detailed documentation of this area has been created, allowing the first studies of the urban character 


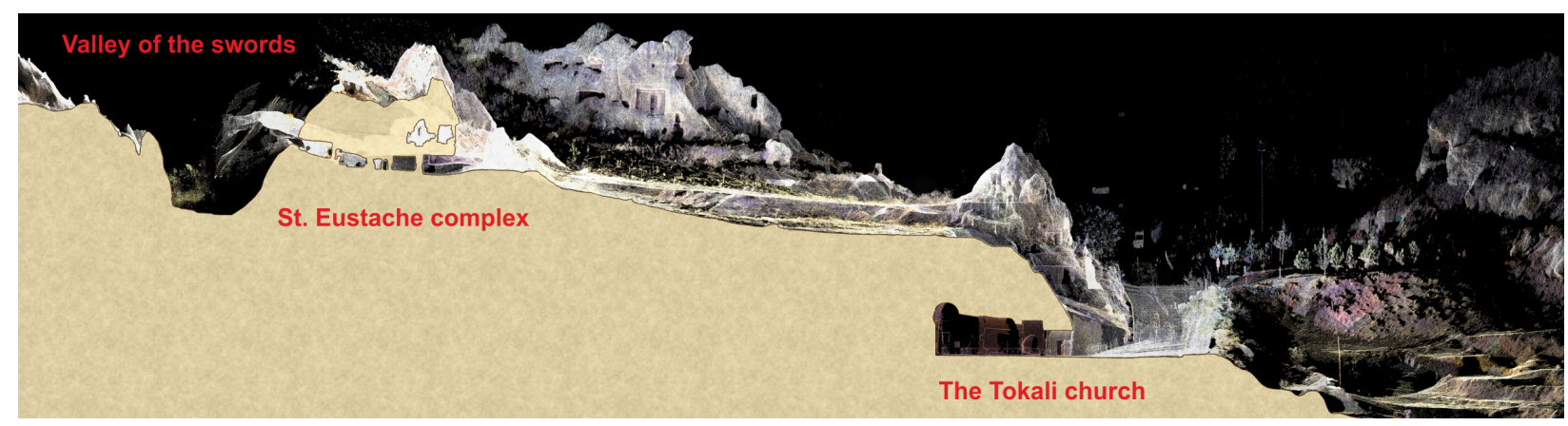

Fig. 4. Cross-section view of the area, starting with the Sword Valley (on the left), then the church of Saint Eustache to the Open Air Museum (on the right).

of this archaeological site. The research is now focused on a fully digital approach using 3D digital models aimed to investigate, read, preserve the information and disseminate the artistic and cultural values otherwise not easily accessible and continuously at risk for loss because of their decay process. The survey of orography and of the articulated buildings with laser scanner is the first complete and detailed documentation of this settlement with an advanced technology and will enable exhaustive studies and the integration of the studies in the progress of the church and of the defensive system of the settlement.

The complex survey of the settlements has required a large number of scans, especially for the narrow passages and the rooms with low-level ceilings (fig. 3). At each arrival point of the tunnel to the "Valley of the Swords" a denser scanning was operated to collect useful data to the alignment of the opposite side of the valley. The fieldwork, in three campaigns, has produced thousands of scans. In most of the situations, the general point density at $5 \mathrm{~m}$ distance is $3 \mathrm{~mm}$ and the quality achieved $+/-2 \mathrm{~mm}$. Outside the complex morphology of the pinnacles needed many scanning stations to cover the corrugated surfaces and to have sufficient natural targets for the registration of each set of scans. The scan stations were close to the surface from $60 \mathrm{~cm}$ for the lower parts to $25 / 30 \mathrm{~m}$ for the upper parts of the pinna- cles. The same definition of quality has been used for the interiors, whose amplitudes never exceed seven metres. The point density at 5 mdistance is $6 \mathrm{~mm}$ and the quality achieved $+/-5 \mathrm{~mm}$ only for small rooms, narrow tunnels and passages. The external routes of the scans have been tracked with a GPS palm unit and some way-points were taken out of each tunnel. This was done for reference and for data organisation, but was not used in the final alignment of the scans.

\section{D Data Treatments}

The first data processing was performed using Cam/2 Faro Scene, Z+F Laser Control and Riegl Riscan: the original scan files (FLS, ZFS and 3DD) were processed, filtered and (where available) collimated with images taken by the same instrument, or by additional cameras and then exported in PTX or PTS exchange format. The alignment operation of all the scans was performed using Leica Geosystem Cyclone. For each scan a set of at least 5 points was selected, identified by markers or natural and/or artificial elements, easily and clearly visible by multiple scans; these points were chosen not aligned, with different heights and distances, conveniently distributed in the scanned space; all the points have been manually chosen. During the registration/alignment process the maximum error accepted was around $0.01 \mathrm{Mt}$. in the pre-alignment of the markers; in a later process it was always applied the so called "cloud-constraint" to allow a significant reduction of the alignment error and the realisation of an optimal result. Obviously this is a very time consum- 


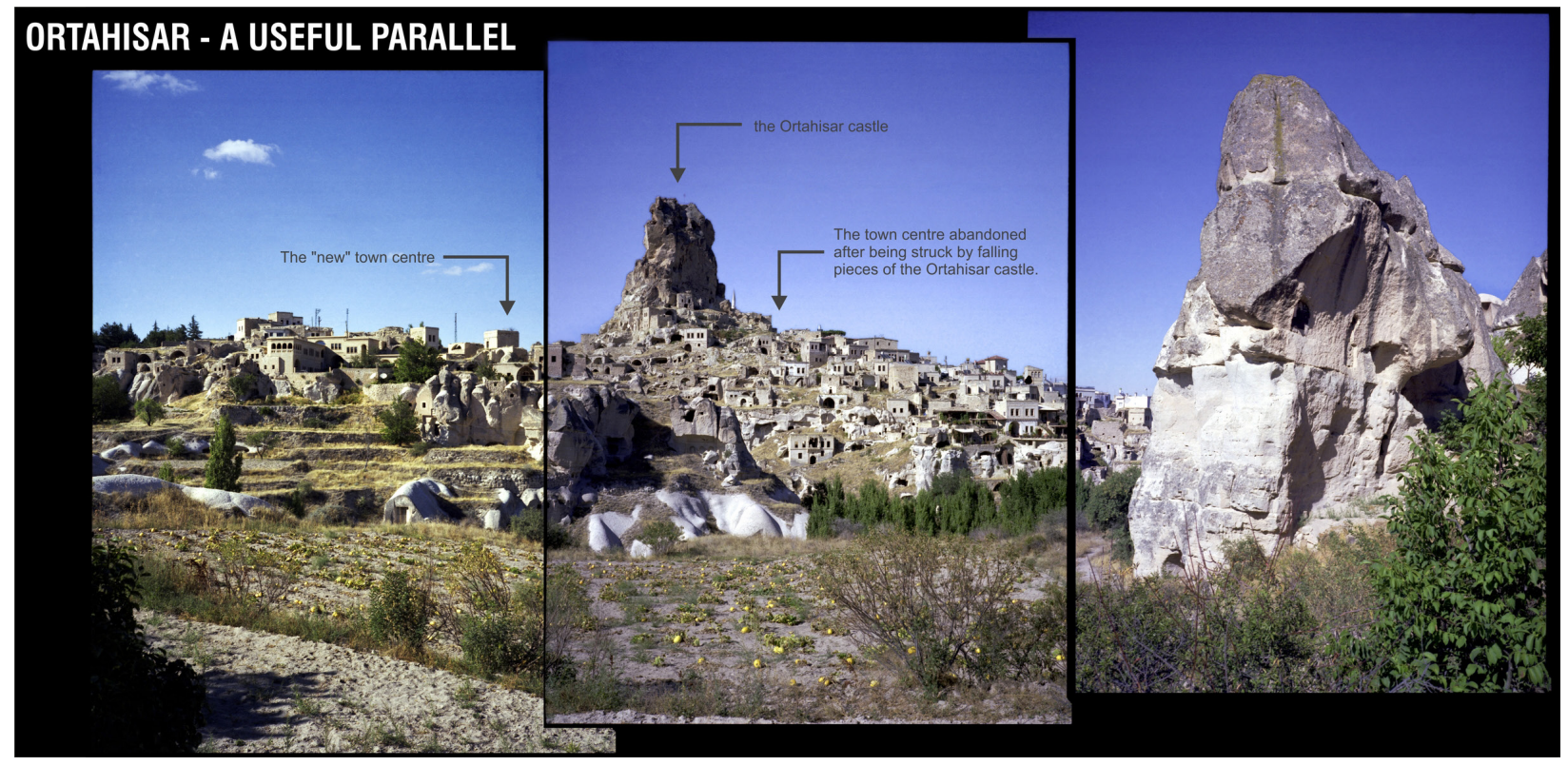

Fig. 5. View of Ortahisar, falling parts of the Ortahisar castle have created a very particular urban condition (copyright G. Verdiani).

ing task, but the subdivision of the work in various datasets, its distribution across three years of survey campaigns and the great quality obtained in the resulting alignment accuracy, proved how worthwhile was this effort.

The overall dataset scans was organised in thematic sets. For example, the total aligned point cloud was later divided in eight groups:

1) the plateau,

2) the front of the church,

3) the side and tops,

4) first series of rooms and the main tunnel,

5) second series of rooms and tunnels,

6) third series of rooms and tunnels,

7) the inside of the church, and

8) the Valley of the Swords (fig. 4).

Starting from this data, further data treatment was carried out, with some optimisation on ghostly elements (rare passing people and vehicles, some minor unfiltered remains) and the extraction/ exporting of data towards other software. One of the first post-processing tasks was the production of simple 2D drawings. Plans, sections and elevations are the typical solutions and in a certain way can be seen as "old" solutions, but they are easy to use, allow annotation and transfer of information because of the well codified language and have easy transfer of the contents between different software. With a subject like rupestrian architecture, such drawing can bring more than one surprise. The production of surface 3D models are so far limited to partial elements, but in the next stage the realisation of general high quality models is planned for use in graphical rendering and as a base for digital reconstruction and hypothesis. Also planned are multimedia models based on simplified versions of the previous models; and partial models for specific use li.e., analysis, 3D printing). The extraction of 2D views has been conducted, with a careful selection of "reference planes" associated to the "cut planes", from the set of selected views, the bases for these drawing were extracted in the form of clear images. For all environmental views and sections, orthogonal views have been created. They reflect solutions coming from traditional graphics, useful for an easy reading of environments that were otherwise impossible even to be photographed. Afterwards, to get a good quality performance for representative and monumental architectures, the point clouds and/or the surfaces were remapped to make models capable to better describe the 
aspect of the real, taking advantage of advanced rendering solutions (Verdiani, 2010).

To allow good coverage for all the possible texturing needs, an extended photographic campaign was done for all the most important elements in the area. For all the dark spaces and structures with "impossible" or "not that useful" conditions in front of a specific photographic campaign, the presentation is done using only the point clouds without colours. Furthermore, the photographic survey describes every single architectural element and some specific shots were taken to better capture the relationships with the landscape and the environment. As a secondary task, but with very meaningful and impressive results, a set of 360 panoramic shots were taken. This was done using two panoramic tripod heads, one mechanical and the second motorised, mounting digital SLR cameras (from 10 to $18 \mathrm{Mp}$ sensors). The whole set of interactive panoramic views were linked to an interactive route with virtual tour to allow a visit to these architectures in their own landscape (fig. 5).

\section{Conclusion}

The survey with 3D laser scanners, for its quality, has been an invaluable tool: the 3D models being produced allow measurement and analysis, for all interested scholars, of the whole existing rock-cut urban system. This complete and extended document will be used to:

1) Analyse and define the relationships of the inter-penetrating spaces;

2) Supply an efficacious support to the documentation originated from the analysis of the underground morphologies and excavation techniques, from the archaeometric data, and from the identification of manifold phases of utilisation, collected during the speleo-archaeological and geological surveys;

3) Study the state of preservation of the rock-cut structures and give an accurate base to plan their consolidation;

4) Develop an accessibility project able to save the environmental and cultural peculiarity of this exceptional rupestrian heritage, improving management in respect of security needs; and

5) Deepen knowledge of the relationships with the extant urban fabric and those destroyed over time, to interpret the original general urban context and life system in which the churches have been conceived and realised.

All this will be done starting from a specific set of 3D models, related to each other and to the other datasets, which are being processed now in the project to respond to the cultural needs of different users and of different requirements of knowledge, an important phase, before beginning dissemination of the results.

\section{Acknowledgements}

The research mission in Cappadocia of the University of Tuscia Rock Paintings in Cappadocia. For a Project of Knowledge, Conservation and Enhancement, directed Maria Andaloro, is composed by multiple research units. The group working on this research from DISBEC is composed of M. Andaloro (coordinator); M. Benucci, C. Bordino, P. Pogliani, D. Sgherri, M. Viscontini, C. Pelosi (chemistry); G. Alfano, D. Ventura, S. Amato, A. Levi and G. Bordi. At the 2012 campaign took part: A. Bixio, R. Bixio, A. De Pascale, A. Maifredi, G. Mirocle Crisci, N. Rovella, S. A. Ruffolo, S. Marabini, L. Alberti, F. Acikgöz, A. Arcudi, S. Borghini, C. Caldi, G. Dikilitaș, S. Scioscia, M. Cristina Tomassetti, 0. Toprak Cihan, V. Valentini and U. Yalçınkaya (restorers). The group working on this research from DIDA (Department of Architecture, Florence) is composed by C. Crescenzi (coordinator), M. Scalzo, G. Verdiani, F. Tioli, A. Pasquali, C. Giustiniani, T. Pignatale, A. Leonardi and G. Tarabella. The Digital Survey of Saint Eustache and Meryemana was operated by G. Verdiani, S. Di Tondo and C. Giustiniani. The territorial survey was operated by F. Tioli, C. Giustiniani and G. Tarabella. The Digital Survey of the Saint Daniel and of all the area between the Meryemana and the Saint Eustache convent, was operated by G. Verdiani, A. Pasqua- 
Li, T. Pignatale, A. Leonardi and A. Mancuso. The digital survey of some peaks around the lower part of the open air museum area was operated by $\mathrm{C}$. Crescenzi and S. Menconero. The data treatment and the post processing phases were operated by G. Verdiani, S. Di Tondo, C. Crescenzi, C. Giustiniani, T. Pignatale, A. Charalambous, V. Niccolini, C. Gira and F. Rafanelli. The successful development of our work in Cappadocia was made possible by the permission and support accorded to the mission by the General Direction of Monuments and Museums of the Turkish Republic. Many thanks to Murat Gulyaz, director of the Archeological Museum of Nevșehir, who has always enthusiastically supported our activities in the territory. For the 2012 survey, in particular, we are greatly indebted to the two Cultural Ministry Deputies, Metin Çakar from the Archaeological Museum of Çorum, and Gultekin Yanbeyi from the Department of Archaeology of the General Direction of Monuments and Museums.

\section{References}

Andaloro M, R Bixio \& C Crescenzi 2013: The complex of $\mathrm{S}$. Eustachius in Göreme, Cappadocia reading the relationship between the landscape and a very articulated underground settlement", proceedings of the Cultural Heritage and New Technologies 18th Conference, Vienna, viewed 10 December 2015, http://www.chnt.at/wp-content/uploads/Andaloro_ etal_2014.pdf

Andaloro M, T Pignatale \& G Verdiani 2013: The church of Meryem Ana in Göreme, Cappadocia, correct documentation for a meaningful heritage at risk, proceedings of the Cultural Heritage and New Technologies 18th Conference, Vienna, viewed 10 December 2015, http://www.chnt.at/wp-content/uploads/Andaloro_etal_2_2014.pdf

Andaloro M, C Crescenzi, P Pogliani \& G Verdiani 2013: The St. Eustache and the Meryemana churches in Göreme. Two case studies of documentation about rupestrian heritage in Cappadocia, technical approach from the digital survey to the restoration hypothesis, in Digital Heritage International Congress
(DigitalHeritage), vol 1, 247. http://www.digitalheritage2013.org/

Index = https://www.academia.edu/8955407/

DigitalHeritage_2013_Proceedings_of_

the_1st_International_Congress_on_Digital_

Heritage_federating_the_19th_Intl_VSMM_10th_Eu-

rographics_GCH_and_2nd_UNESCO_Memory_of_

the_World_Conferences_plus_special_sessions_ from_CAA_Arqueologica_2.0_Space2Place_ICOMOS_ ICIP_and_CIPA_EU_Projects_et_al

Bixio R \& V Castellani 1995: Tipologia delle strutture sotterranee in Cappadocia, in Bertucci G, Bixio R \& Traverso M (ed.), Le città sotterranee della Cappadocia: 106-120. Erga Edizioni, Genova.

Bixio R, V Castellani \& C Succhiarelli 2002: Cappadocia. Le città sotterranee, Istituto Poligrafico e Zecca dello Stato, Rome.

Bixio R, V Caloi, A De Pascale, V Castellani, M Traverso, J Triolet \& L Triolet 2012: Cappadocia, records of underground sites, Archaeopress, Oxford.

Crescenzi C, 2012: Rupestrian landscape and settlements Workshops and Survey Results, Tipografia il David, Firenze.

Crescenzi C \& G Verdiani 2012: The CHRIMA project: Investigating the rupestrian architecture in the Mediterranean area, proceedings of the Cultural Heritage and New Technologies 17th Conference, 1, 1-11, Vienna, viewed 10 December 2015, http://www.chnt. at/wp-content/uploads/eBook_CHNT17_Crescenzi_Verdiani.pdf

Crescenzi C, S Di Tondo \& G Verdiani 2012: Kültürel Miras için araștirmalar ve interaktif multimeddya belgeler, in Oger A (ed.), 1. Uluslararası Nevșehir Tarih ve Kültür Sempozyumu bildirileri : 16-19 Kasım 2011, Nevșehir, vol. 2: 111-130. Nevșehir Üniversitesi Kapadokya Araștırma ve Uygulama Merkezi (NEVKAM), Nevșheir.

De Pascale A \& R Bixio 2015: Defensive devices in ancient underground shelters. Comparison among the sites of Aydıntepe, Ani, Ahlat and Cappadocia, in Turkey, in Ișıklı M \& Can B (ed.), International Symposium on Eastern Anatolia - South Caucasus Cultures, Proceedings II, vol 1: 461-80. Cambridge Scholars Publishing, Newcastle upon Tyne, UK. Jolivet-Lévy C, 1991: Les églises byzantines de Cappadoce: le programme iconographique de l'abside 
et de ses abords, Editions du Centre national de la recherche scientifique, Paris.

Jolivet-Lévy C, 2002: La Cappadoce médiévale: images et spiritualité, Saint-Léger-Vauban 2001, trad. it. L'arte della Cappadocia, Milan.

Verdiani G (ed.) 2011: Il ritorno all'immagine, nuove procedure image based per il Cultural Heritage, Lulu.com. 
